Journal of Sport Coaching and Physical Education 3 (1) (2018)

\title{
PENINGKATAN KECEPATAN RENANG 50 METER GAYA DADA
}

\section{Herawan Chrisnanto ${ }^{\bowtie}$}

Jurusan Pendidikan dan Kepelatihan Olahraga, Fakultas Ilmu Keolahragaan, Universitas Negeri Semarang, Indonesia

\section{Info Artikel}

Sejarah Artikel:

Diterima Maret 2018

Disetujui April 2018

Dipublikasikan Agustus 2018

Keywords:

Renang, Gaya Dada,

Latihan, Kecepatan

\begin{abstract}
Abstrak
Tujuan penelitian untuk mengetahui pengaruh latihan Renang 50 meter gaya dada repetisi meningkat set tetap dan repetisi tetap set meningkat terhadap kecepatan $50 \mathrm{~m}$ gaya dada atlet putra PR. Bhumi Phala Temanggung tahun 2017. Metode penelitiannya eksperimen dengan hasil berupa data kuantitatif. Populasi penelitian atlet putra kelompok umur III PR. Bhumi Phala Temanggung tahun 2017 berjumlah 4 orang. Isntrumen penelitian adalah, tes kecepatan renang 50m gaya dada. Data hasil tes dianalisis menggunakan rumus t-test pada taraf kesalahan 5\%.Berdasarkan uji $\mathrm{t}$ diperoleh nilai $t_{\text {hitung }}$ sebesar 4.375 pada kelompok repetisi tetap set meningkat dan $t_{\text {hitung }}$ sebesar 3.12 pada kelompok repetisi meningkat set tetap dengan $\mathrm{db} 1$ dimana nilai $\mathrm{t}_{\text {tabel }}$-nya pada taraf signifikansi $5 \%$ yaitu 12.70 , maka kedua $t_{\text {hitung }}$ lebih kecil dari $t_{\text {tabel }}$ sehingga dijelaskan kedua latihan tersebut tidak ada pengaruhnya. Simpulan penelitian ini adalah tidak ada pengaruh signifikan antara latihan renang repetisi meningkat set tetap dan repetisi tetap set meningkat terhadap kecepatan renang $50 \mathrm{~m}$ gaya dada. Saran bagi pelatih dalam melatih kecepatan $50 \mathrm{~m}$ gaya dada sebaiknya latihan renang repetisi tetap set meningkat, latihan dapat divariasikan dengan laihan repetisi meningkat set tetap.
\end{abstract}

\begin{abstract}
The aim of the study was to determine the effect of 50 meter breaststroke repetition training to increase the fixed set and fixed repetition set to increase the speed of $50 \mathrm{~m}$ breaststroke of male PR athletes. Bhumi Phala Temanggung in 2017. The research method is an experiment with the results in the form of quantitative data. Study population of male athletes in age group III PR. Bhumi Phala Temanggung in 2017 is 4 people. The research instrument is a $50 \mathrm{~m}$ breaststroke speed test. The test results data were analyzed using the t-test formula at the error level of 5\%. Based on the t test obtained a tcount of 4.375 in the set fixed repetition group increases and tcount of 3.12 in the repetition group increases the fixed set with $d b 1$ where the ttable value is at the significance level 5\%, namely 12.70, then the two tcounts are smaller than table so that the two exercises are explained to have no effect. The conclusion of this study is that there is no significant effect between swimming training repetitions increasing fixed sets and fixed set repetitions increasing with $50 \mathrm{~m}$ breaststroke swimming speed. Suggestions for trainers in training the $50 \mathrm{~m}$ breaststroke speed should exercise swimming fixed repetition set increases, training can be varied with the repetition increased the fixed set.
\end{abstract}

(C) 2018 Universitas Negeri Semarang

\footnotetext{
Alamat korespondensi:

Gedung F1 Lantai 3 FIK Unnes

Kampus Sekaran, Gunungpati, Semarang, 50229

E-mail:
}

ISSN 2548-4885 


\section{PENDAHULUAN}

Olahraga renang merupakan olahraga yang sudah ada sejak 3500 sebelum Masehi oleh bangsa Mesir purba yang kala itu digunakan sebagai alat beladiri untuk menghadapi tantangan alam (Muhajir, 2007:88). Dalam pesta olahraga mutievent seperti PON, SEA Games, Asian Games dan Olimpiade renang merupakan salah satu dari tiga cebang olahraga (selain atletik dan senam) yang wajib dipertandingkan.

Dalam olahraga renang terdapat empat macam gaya yang dipertandingkan yaitu gaya kupu-kupu (butterfly), gaya punggung (backcrawl), gaya dada (breaststroke), dan gaya crawl (freestyle). Renang gaya dada menjadi popular ketika pada tahun 1875 , perenang Inggris, Matthew Webb menjadi orang pertama yang merenangi Teluk Channel dengan menggunakan gaya ini. Gaya dada/ breaststroke ini gerakanya menyerupai katak yang sedang berenang, sehingga oleh sebagian kalangan disebut gaya katak. Perbedaanya, pada manusia sikap meluncurnya dilakukan dengan kedua kaki lurus, sedang pada katak hal tersebut tidak dijumpai.

Dalam suatu pertandingan olahraga pasti akan menghasilkan juarajuara dimana untuk melahirkan seorang juara, memerlukan proses yang panjang. Dalam proses tersebut harus diatur secara sistematis, terencana, terarah, dan berkesinambungan yaitu melalui latihan. Menurut Harsono (1988:101), latihan adalah proses yang sistematis dari berlatih dan bekerja yang dilakukan secara berulang-ulang dengan kian hari kian menambah jumlah bebanya. Dalam latihan perlu dikembangkan beberapa aspek, yaitu, aspek psikologis dan fisiologis, aspek fisik baik umum maupun khusus, aspek teknik, aspek taktik dan setrategi, dan aspek mental.

Latihan berupa renangan yang berulang-ulang harus dilaksanakan secara sistematis dan memperhatikan prinsipprinsip latihan. Dalam hal ini Harsono (1988:101), menyatakan bahwa sistematis yang dimaksud adalah terencana, sesuai jadwal, secara metodis atau dari mudah ke sukar. Latihan makin lama makin meningkat, baik intensitas, volume, repetisi maupun setnya. Namun kenaikan tersebut harus sedikit demi sedikit karena untuk menjaga agar tidak terjadi overtraining sehingga atlet dapat bertahan terhadap stress-stress yang ditimbulkan oleh latihan berat tersebut, serta proses adaptasi atlet terhadap beban latihan akan terjamin keteraturanya.

Dalam suatu progam latihan pelatih harus menggunakan jumlah set dan repetisi yang sesuai dengan kemampuan atlet, agar target yang diinginkan bisa tercapai. Sajoto (1995:34) menyatakan bahwa repetisi adalah jumlah ulangan mengangkat beban dan set adalah suatu rangkaian kegiatan dari beberapa repetisi Menurut Harsono (1988:191), latihan menggunakan repetisi sedikit dengan beban yang berat akan membentuk kekuatan, sedangkan menggunakan repetisi banyak, dengan beban ringan akan membentuk daya tahan otot. Latihan kekuatan dan daya tahan perlu dikembangkan dalam melatih kecepatan (Harsono, 1988:216). Dalam penelitian ini, jumlah beban dimanipulasi dengan banyaknya set dan repetisi dalam latihan.

Dari uraian di atas, peneliti ingin mengadakan penelitian tentang renang gaya dada/breaststroke yang berjudul: Peningkatan kecepatan renang 50 meter gaya dada dengan latihan repetisi tetap set meningkat dan repetisi meningkat set tetap (Eksperimen pada atlet putra 
perkumpulan renang Bhumi Phala Temanggung tahun 2017).

Dari latar belakang masalah yang telah diuraikan dapat di identifikasi beberapa masalah sebagai berikut:

Belum diketahuinya pengaruh latihan renang gaya dada repetisi meningkat set tetap terhadap kecepatan renang 50 meter gaya dada atlet putra Perkumpulan Renang Bhumi Phala Temanggung tahun 2017.

Belum diketahuinya pengaruh latihan renang gaya dada dengan repetisi tetap set meningkat terhadap kecepatan renang $50 \mathrm{~m}$ gaya dada atlet putra Perkumpulan Renang Bhumi Phala Temanggung tahun 2017.

Belum diketahuinya perbedaan pengaruh antara latihan renang gaya dada dengan repetisi tetap set meningkat dan repetisi meningkat set tetap terhadap kecepatan renang 50 meter gaya breaststroke atlet putra Perkumpulan Renang Bhumi Phala Temanggung tahun 2017.

Berdasarkan latar belakang masalah dan identifikasi masalah yang telah disebutkan serta terbatasnya waktu dan keterbatasan-keterbatasan yang lain, sehingga perlu diberi batasan masalah secara maka peneliti hanya akan mengkaji dan mengetahui perbandingan kecepatan renang 50 meter gaya dada antara atlet yang diberikan progam latihan repetisi tetap, set meningkat dengan repetisi meningkat set meningkat pada atlet putra di Perkumpulan Renang Bhumi Phala Temanggung pada tahun 2017

Penelitian ini bertujuan untuk mengetahui: Mengetahui pengaruh latihan renang gaya dada dengan repetisi tetap set meningkat terhadap kecepatan renang 50 meter gaya dada atlet putra Perkumpulan Renang Bhumi Phala Temanggung tahun 2017.
Mengetahui pengaruh latihan renang gaya dada dengan repetisi meningkat set tetap terhadap kecepatan renang 50 meter gaya dada atlet putra Perkumpulan Renang Bhumi Phala Temanggung tahun 2017.

Mengetahui perbedaan pengaruh antara latihan renang gaya dada dengan repetisi tetap set meningkat dan repetisi meningkat set tetap terhadap kecepatan renang 50 meter gaya dada atlet putra Perkumpulan Renang Bhumi Phala Temanggung tahun 2017.

Manfaat dari penelitian ini bagi ilmu kepelatihan olahraga mengenai pengaruh latihan renang gaya dada dengan repetisi tetap set meningkat dan repetisi meningkat set meningkat terhadap kecepatan renang $50 \mathrm{~m}$ gaya dada. Manfaat praktis: memberi manfaat untuk meningkatkan prestasi atlet-atlet renang di Temanggung.

\section{Renang}

Renang adalah olahraga yang melombakan kecepatan atlet renang dalam berenang. Renang adalah menggerakkan badan melintas, mengapung atau menyelam di air menggunakan kaki dan tangan (Depdikbud, 2000:964). Dalam olahraga renang terdapat 4 nomor gaya yang dipertandingkan, yaitu gaya kupu-kupu (butterfly), gaya punggung (backcrawl), gaya dada (breaststroke), dan gaya bebas (freestyle).

\section{Gaya dada (breaststroke)}

Gaya dada adalah gaya dalam renang yang dilakukan dengan melakukan kayuhan dan tendangan secara bergantian. Gerakan kayuhan gaya dada dilakukan di bawah permukaan air dengan tarikan tidak melebihi pinggang kecuali saat awalan. Posisi tubuh pada gaya dada mirip dengan gaya kupu-kupu, yaitu berubah-ubah: pertama, posisi awal 
sebelum lengan dan tungkai di bawah permukaan air. Kedua, wajah atau kepala mulai diangkat ke permukaan air selama kayuhan lengan dan keluar dari permukaan air untuk mengambil napas. Ketiga, tubuh lebih rendah dari kepala dan tungkai lebih rendah dari badan saat tungkai melakukan recovery. Dalam perlombaan renang gaya dada, kedua tangan harus menyentuh dinding secara bersamaan saat pembalikan maupun finish.

\section{Repetisi}

Repetisi adalah banyaknya jumlah ulangan gerakan/rangsangan yang sama dalam waktu tertentu. Repetisi tetap adalah jumlah ulangan gerakan yang sama, dimana jumlahnya tidak berubah dalam kurun waktu tertentu, sedangkan repetisi meningkat adalah jumlah ulangan gerakan yang sama, dimana jumlahnya semakin meningkat dalam kurun waktu tertentu

Set

Set adalah sekumpulan dari beberapa rangkaian repetisi dari suatu angkatan latihan (Sajoto,1995: 34). Set tetap adalah kumpulan dari beberapa repetisi dari suatu angkatan latihan dimana jumlahnya tidak berubah dalam kurun waktu tertentu, sedangkan set meningkat adalah kumpulan dari beberapa repetisi dalam suatu angkatan latihan dimana jumlahnya semakin meningkat dalam kurun waktu tertentu.

\section{Repetisi meningkat set tetap}

Yang dimaksud repetisi meningkat set tetap adalah adanya peningkatan pada jumlah ulangan per item latihan (repetisi) dan tidak ada peningkatan pada setiap kumpulan jumlah ulangan (set) dalam kurun waktu tertentu.

\section{Repetisi tetap set meningkat}

Yang dimaksud repetisi tetap set meningkat adalah tidak ada peningkatan pada jumlah ulangan per item latihan (repetisi) dan adanya peningkatan pada setiap kumpulan jumlah ulangan (set) dalam kurun waktu tertentu.

\section{Intensitas latihan}

Intensitas adalah besarnya beban latihan yang harus diselesaikan dalam waktu tertentu. Ukuran yang menunjukan kualitas suatu rangsang yang diberikan selama latihan berlangsung

\section{Recovery}

Waktu istirahat yang diberikan antar set pada saat latihan berlangsung.

\section{Interval}

Waktu istirahat antar yang diberikan antar seri, atau antar sesi per unit latihan.

Latihan menggunakan repetisi sedikit dengan beban berat akan membentuk kekuatan, sedangkan latihan menggunakan repetisi banyak dengan beban ringan akan menghasilkan perkembangan daya tahan otot (Harsono, 1988:191). Kecepatan merupakan kemampuan untuk melakukan gerakangerakan yang sejenis secara berturut-turut dalam waktu yang sesingkat-singkatnya. Kecepatan tergantung dari beberapa faktor yaitu kekuatan, fleksibilitas, dan reaksi, sehingga dalam melatih kecepatan, tidak hanya unsur kecepatan saja yang dilatih, tetapi unsur yang lain seperti kekuatan dan daya tahan juga harus dilatih. Hal tersebut didukung oleh hasil riset Leningrad Physical Culture Research Institude yang menyatakan bahwa kelompok yang hanya diberi latihan kecepatan saja maka kekuatanya berkembang $10 \%$ dan kecepatanya $15 \%$. Sedangkan kelompok yang diberi latihan kekuatan, kecepatan dan daya tahan, kekuatanya berkembang 30\%, kecepatan $40 \%$ dan daya tahan 35\% (Harsono, 1988:216). Dalam olahraga renang, untuk mencapai prestasi yang optimal perlu didukung kemampuan fisik yang 
memadai. Peningkatan kondisi fisik dalam renang dapat dilakukan di darat dan di air. Latihan di darat digunakan untuk meningkatkan daya tahan otot lokal, sedangkan latihan di air berguna untuk meningkatkan daya tahan cardiorespiratory.

Latihan repetisi: latihan renang yang mengambil jarak lebih pendek dan dengan kecepatan yang tinggi dari nomer spesialisnya. Dalam latihan ini, perenang tidak menggunakan seluruh tenaganya, namun berenang dengan kecepatan yang tinggi dan terkontrol. Istirahat antar renangan cukup lama sehingga denyut jantung dan pernapasan hampir pulih kembali. Waktu istirahat antar renangan sekurang-kurangnya tiga kali lamanya waktu yang digunakan untuk melakukan renangan (Soekarno, 1982:315). Latihan repetisi lebih menekankan unsur kecepatan sedangkan daya tahan hanya sedikit (Soejoko Hendromartono, 1992:41). Tujuan dari latihan repetisi adalah untuk meningkatkan kecepatan dan membiasakan berenang dengan kecepatan yang ingin dilakukan saat perlombaan

\section{METODE}

Dalam metode ini digunakan metode eksperimen untuk memperoleh data yang sesuai. Metode eksperimen adalah kegiatan untuk meneliti suatu gejala yang timbul sebagai dari akibat dari latihan atau perlakuan. Dasar penggunaan metode eksperimen adalah kegiatan yang diawali dengan memberikan perlakuan terhadap subyek dan diakhiri dengan tes untuk menguji kebenarannya. Pembagian menjadi dua kelompok dimana hal ini diperoleh dari hasil matching nilai rata-rata grup dari test awal, sehingga kedua grup berangkat dari titik tolak yang sama. Rancangan penelitian menggunakan desain pre-test dan post-test.

Dalam penelitian ini untuk menyeimbagkan kedua grup tersebut dengan cara subject matching ordinal pairing yaitu mengurutkan hasil kecepatan renang gaya breaststroke 50 meter dari sempel mulai dari tercepat ke yang paling lambat dalam tes awal. Hasil yang sudah urut kemudian dipasangkan yaitu antara subyek yang hasilanya sama atau hampir sama menggunakan rumus A-B-B-A, kemudian anggota-anggota dari setiap pasangan dipisahkan ke dalam grup eksperimen I dan grup eksperimen II

Desain penelitian dapat di gambarkan sebagi berikut :

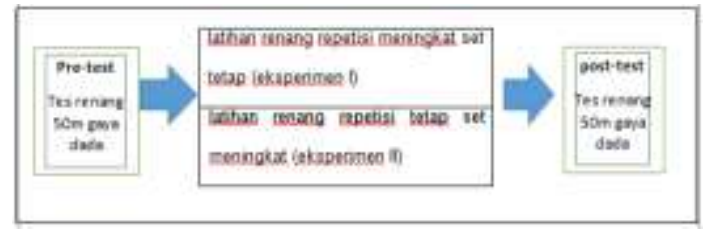

Gambar 1. Desain Penelitian

Variabel bebas dalam penelitian ini adalah latihan renang gaya dada repetisi tetap set meningat. Latihan renang gaya dada repetisi meningkat set tetap.Variabel terikat dalam penelitian ini adalah kecepatan renang 50 meter gaya dada.

Populasi dalam penelitian ini adalah atlet putra perkumpulan renang Bhumi Phala Temanggung yang berjumlah 13 orang

Sempel dalam penelitian ini adalah atlet putra Perkumpulan Renang Bhumi Phala Temanggung yang berumur 12-13 tahun (KU III) berjumlah 4 atlet. Dalam penelitian ini teknik pengambilan sampel adalah purposive sample, yaitu dari sejumlah populasi yang ada, untuk menjadi sampel harus memenuhi ketentuan-ketentuan sesuai dengan tujuan penelitian. Adapun ketentuan- 
ketentuan dalam tujuan penelitian tersebut adalah sebagai berikut:

\section{Instrumen Penelitian}

Dalam penelitian ini, alat dan fasilitas yang digunakan paneliti adalah sebagai berikut:

Kolam renang panjang: panjang kolam yang digunakan adalah 50 meter dengan lebar 21 meter yang terdiri dari 8 lintasan

\section{Pelampung \\ Pullbouys \\ Paddle \\ Stopwatch \\ Peluit}

Alat tulis

Instrument yang digunakan dalam penelitian ini adalah tes renang 50 meter gaya breaststroke untuk pre-test dan posttest.

\section{Pre test}

Tes awal (pre test) adalah tes untuk mengukur kemampuan sampel sebelum mendapat latihan. Kemudian hasil yang diperoleh dipakai sebagai pedoman untuk menentukan kelompok eksperimen yang akan mendapatkan latihan renang gaya dada dengan repetisi tetap set meningkat atau mendapatkan latihan gaya breaststroke dengan repetisi meningkat set tetap. Selanjutnya dari waktu yang sudah didapat lalu diurutkan sesua rangking dipasangkan dengan rumus "A-B-B-A" sehingga akan mendapatkan dua atlet yang akan diberi progam latihan renang gaya dada dengan repetisi tetap set meningkat dan 2 atlet yang akan diberi progam latihan dengan gaya dada dengan repetisi meningkat set tetap.

\section{Perlakuan (Treatment )}

Prinsip latihan dalam penelitian ini adalah untuk meningkatkan kecepatan renang 50 meter gaya dada pada atlet putra KU III Perkumpulan Renang Bhumi Phala Temangung. Melatih suatu kecepatan dari atlet dibutuhkan jangka waktu tertentu agar diperoleh hasil yang optimal. Latihan dilakukan 4 kali seminggu yaitu pada hari Senin, Selasa, Jum'at, Sabtu, selama 18 kali pertemuan dengan rincian 16 kali pertemuan digunakan untuk latihan dimana tiap latihanya diberi catatan perkembangan tiap atlet, 1 kali pre test, 1 kali post test. Frekuensi latihan 4 kali dalam seminggu sesuai dengan anjuran bahwa latihan dengan frekuensi 3 sampai 5 per minggu lebih berpengaruh dari pada dilakukan satu kali seminggu atau 6 sampai 7 kali per minggu.

\section{Tes Akhir ( Post Test )}

Setelah menjalani treatment selama 16 kali pertemuan, selanjutnya akan dilakukan tes akhir dengan menggunakan tes sprint 50 meter gaya breaststroke untuk melihat hasil akhir setelah diberikan progam latihan renang repetisi tetap set meningkat dan repetisi meningkat set tetap. Prosedur dalam posttest ini adalah atlet melakukan renang sprint 50 meter gaya dada dengan menggunakan 2 lintasan dimana tiap lintasanya diberi 1 time keeper yang dilakukan selama 3 kali percobaan dimana diberi jeda istirahat selama 5 menit. Atlet melakukan sprint 50 meter gaya dada dengan pasangan latihannya masing-masing. Pengambilan waktu dimulai saat atlet bergerak setelah abaaba take your mark lalu peluit dibunyikan.

\section{Teknik Analisis Data}

Apabila perlakuan telah selesai dilakukan maka diakhiri dengan tes akhir (post test) yang bertujuan untuk mengetahui hasil selama latihan, kemudian dilanjutkan dengan tabulasi data untuk menghitung statistik diskriptif. Untuk menguji hipotesis terlebih dahulu dilakukan uji persyaratan 
analisis yaitu uji normalitas data dan uji homogenitas dengan menggunakan Kolmogorov Smirnov dan levene, setelah itu dilanjutkan dengan menggunakan uji-t, untuk memperoleh data diperlukan persyaratan persiapan tabel statistik dan perhitungan statistik. Tabel perhitungan statistik yang digunakan dalam penelitian ini adalah sebagai berikut:

Tabel 1. contoh tabel persiaan perhitungan statistic pola M-S

\begin{tabular}{llllll}
\hline $\begin{array}{l}\text { Pasangan } \\
\text { subjek }\end{array}$ & $X_{1}$ & $X_{2}$ & $\mathrm{D}$ & $\mathrm{d}$ & $d^{2}$ \\
& & & $\left(X_{1}-X_{2}\right)$ & $(\mathrm{D}-\mathrm{MD})$ &
\end{tabular}

Jumlah

Mean

keterangan

$\mathrm{X}_{1}$ : nilai kelompok eksperimen I

$\mathrm{X}_{2} \quad$ : nilai kelompok ekspeimen II

D : jumlah dari perbedaan tiap-tiap pasangan

d : jumlah dari deviasi perbedaan

MD : mean dari kelompok eksperimen I dan eksperimen II

$d^{2} \quad$ : jumlah dari deviasi dari mean perbedaan

Langkah berikutnya setelah data tersusun dalam table adalah melakukan perhitungan, sebagai langkah untuk mengolah data maka digunakan rumus uji t yaitu :

$$
t=\frac{M D}{\sqrt{\frac{\sum d^{2}}{N(N-1)}}}
$$

\section{keterangan}

MD : Mean deference

d : deviasi individual dari $\mathrm{MD}$

$\mathrm{N}$ : jumlah pasangan subjek

Untuk memasukan data ke

dalam t-tes tersebut harus diketahui terlebih dahulu nilai dari mean perbedaan (MD), yaitu dicari dengan rumus:

$$
\mathrm{MD}=\frac{\sum D}{N}
$$

Dan harus dibuktikan bahwa:

$$
\mathrm{D}=X_{1} \quad-X_{2} \text { dan } \mathrm{D}=0
$$

Keterangan

MD : Mean jumlah kelompok eksperimen I dan eksperimen II

$d^{2}$ : jumlah deviasi dari mean perbedaan

$\mathrm{N}$ : jumlah dari subjek

D : jumlah dari perbedaan tiap-tiap pasangan

$\mathrm{D}$ : jumlah dari deviasi perbedaan

$X_{1}$ : nilai kelompok eksperimen I

$X_{2} \quad$ : nilai kelompok eksperimen II

Hipotesis nihil diuji kebenaranya berdasarkan taraf signifikasi 5\% diantara db. 1 dan kemudian akan menolak hipotesis yang benar 5\% diantara 100 . Menolak hipotesis atas dasar sigifikasi 5\% atau benar dalam keputusan $95 \%$.

\section{PEMBAHASAN}

Berdasarkan uji beda data pre-test dan post-test antara kelompok eksperimen I dan kelompok eksperimen II dapat diketahui bahwa tidak ada perbedaan pengaruh yang signifikan antara latihan renang gaya dada dengan repetisi meningkat set tetap dan repetisi tetap set meningkat terhadap kecepatan renang 50 meter gaya dada atlet putra kelompok umur III Perkumpulan Renang Bhumi Phala Temanggung tahun 2017.

Dari hasil analisa data penelitian diketahui bahwa kedua metode latihan renang tersebut sama-sama meningkatkan kecepatan 50 meter gaya dada pada atlet putra KU III Perkumpulan Renang Bhumi Phala Temanggung. Hal tersebut dibuktikan dengan rata-rata hasil post-test kelompok I dan kelompok II yang sama- 
sama mengalami penurunan dibandingkan hasil pre-test. Salah satu penyebab tidak adanya perbedaan yang signifikan pada hasil olah data pre-test dan post-test adalah sedikitnya sampel dalam penelitian ini, sehingga menyebabkan sedikitnya data yang dibandingkan pada saat melakukan uji-t yang berdampak pada sedikitnya hasil t-hitung.

Rata-rata hasil pre-test dan posttest catatan waktu renang 50 meter gaya dada pada kelompok eksperimen I dan kelompok eksperimen II tersebut dapat dijelaskan bahwa pada kelompok eksperimen I yang diberikan latihan renang dengan repetisi meningkat set tetap catatan renangnya turun1.1 detik yaitu dari 45.91 detik menjadi 44.81 detik. Sedangkan pada kelompok eksperimen II yang diberikan latihan latihan renang dengan repetisi tetap set meningkat catatan waktu renangnya turun 1.4 detik yaitu dari 45.39 detik menjadi 43.99 detik hal ini menunjukan bahwa kelompok eksperimen II yang diberikan latihan renang dengan repetisi tetap set meningkat lebih baik dibandingkan dengan kelompok eksperimen I yang diberikan latihan dengan repetisi meningkat set tetap meskipun secara statistik tidak berbeda. Penurunan waktu yang sedikit tidak akan terbukti dalam perhitungan statistik. Namun dalam kenyataan perlombaan renang, selisih waktu 1 detik akan sangat berpengaruh besar terhadap prestasi seorang perenang. Misalkan seorang atlet mempunyai selisih waktu 0.01 detik dengan perenang kedua, maka yang akan menjadi juara tetap perenang pertama yang mempunyai catatan waktu 0.01 lebih cepat daripada perenang kedua.

Perbedaan kecepatan renang 50 meter gaya dada tersebut terjadi karena dalam pelaksanaan latihan renang dengan repetisi tetap set meningkat mendapat istirahat yang lebih banyak karena setnya makin banyak sehingga tidak sampai terjadi kelelahan otot dan kecepatan dapat dijaga. Sedangkan pada latihan repetisi meningkat set tetap waktu istirahat atlet lebih sedikit karena repetisi makin banyak sedangkan setnya tetap sehingga atlet mengalami kelelahan otot yang mengakibatkan atlet tidak bisa maksimal pada set berikutnya sehingga aspek daya tahan yang lebih kena.

Dalam latihan renang, apabila waktu istirahat diperpendek, maka akan terjadi pergeseran dari perkembangan kecepatan menjadi perkembangan daya tahan. Sedangkan bila waktu istirahat ditambah, kualitas dari tiap ulangan renang dapat ditingkatkan sehingga dapat memusatkan pada perkembangan kecepatan. Waktu istirahat yang diperpendek dalam penelitian ini diperoleh dari semakin banyaknya repetisi tiap set dan setnya tetap, sedangkan waktu istirahat yang semakin banyak atau ditambah diperoleh dari set yang semakin banyak dan repetisinya tetap. Berdasarkan keterangan tersebut dapat diketahui bahwa latihan renang gaya dada dengan repetisi meningkat set tetap lebih mengena pada perkembangan daya tahan sedangkan latihan dengan repetisi tetap set meningkat lebih fokus pada usaha perkembangan kecepatan.

\section{SIMPULAN}

Berdasarkan hasil penelitian diatas dapat disimpulkan hal-hal sebagai berikut:

Tidak ada pengaruh yang signifikan latihan renang gaya breaststroke dengan repetisi tetap set meningkat dalam peningkatan kecepatan renang 50 meter gaya breaststroke terhadap atlet putra kelompok umur III Perkumpulan 
Renang Bhumi Phala Temanggung tahun 2017

Tidak ada pengaruh yang signifikan latihan renang gaya breaststroke dengan repetisi tetap set meningkat dalam peningkatan kecepatan renang 50 meter gaya breaststroke terhadap atlet putra kelompok umur III Perkumpulan Renang Bhumi Phala Temanggung tahun 2017

\section{Saran}

Dari simpulan penelitian di atas. Penulis mengajukan saran :

Bagi pelatih dalam melatih kecepatan 50 meter gaya breaststroke sebaiknya latihan renang repetisi tetap set meningkat, selain itu latihan dapat divariasikan dengan latihan menggunakan repetisi meningkat set tetap agar tidak membosankan.

Bagi peneliti lain yang tertarik melakukan penelitian sejenis dapat menjadikan hasil penelitian ini sebagai bahan referensi dan diharapkan menggunakan sempel yang lebih banyak supaya hasil penelitian lebih akurat.

\section{DAFTAR PUSTAKA}

Agung Purwandono Saleh. 2008. Olahraga Renang. Yogyakarta: Wimaya Press

Depdikbud. 2000. Kamus Besas Bahasa Indonesia. Jakarta: Balai Pustaka

Hannula, D. 1995. Sukses Melatih Renang Edisi Kedua. Terjemahan Margarita Nining Astuti. 2003. Yogyakarta: Pustaka Insan Madani

Harsono. 1988. Choaching dan ApekAspek Psikologis Dalam Choaching. Jakarta : Depdikbud Imam Hidayat. 1997. Biomekanika. Bandung: IKIP Bandung
Iwan Kristono. 1986. Kamus Istilah Olahraga. Solo: Tiga Serangkai

Maglischo, Ernest. W, 1993, Swimming Even Fastest. California: Mayfield Pubish Company

Mochamad Sajoto, 1988. Pembinaan Kondisi Fisik Dalam Olahraga. Jakarta: Depdikbud

-----, 1995. Peningkatan dan Pembinaan Kekuatan Kondisi Fisik Dalam Olahraga. Semarang. Dahara Prize

Muhajir. 2007. Pendidikan Jasmani Olahraga dan Kesehatan SMA Kelas $X$ Jakarta: Erlangga

Rubiyanto Hadi. 2007. Ilmu Kepelatihan Dasar. Semarang: Rumah Indonesia

Soejoko Hendromartono. 1992. Olahrahga Pilihan Renang.jakarta: Depdikbud

Soekarno. 1982. Pengetahuan Mengenai Renang. Yogyakarta: Dikti Depdikbud

Suharno H.P. 1986. Ilmu Kepelatihan Olahraga. Yogyakarta: IKIP Yogyakarta

Suharsimi Arikunto. 2010. Prosedur Penelitian. Yogyakarta: Rineka Cipta

Sutrisno Hadi. 2015. Metodologi Riset. Yogyakarta: Pustaka Pelajar

Undang-Undang Republik Indonesia No. 3 Tahun 2005. Yogyakarta: Pustaka Yustisia 